\title{
LA FERIA DE LA CIENCIA
}

(Un factor importante para el mejoramiento de la enseñanza de la ciencia) *

\section{Antecedentes y justificación}

Evolución Histórica. La Feria de la Ciencia es un acontecimiento científico que se realiza en casi todos los países del mundo, con regularidad de uno o dos años. Los países socialistas, por ejemplo, la realizan con el nombre de "las espartaquiadas" y resultan ser programas de concurso de selección a niveles varios en las ciencias física, matemática, biología, química y también en educación física, con sus competencias deportivas.

Estos concursos son realizados a nivel de escuelas, luego distritos y finalmente a nivel nacional. Países como Noruega, Dinamarca y muchos otros en Europa, realizan estos eventos con características parecidas a las de los países socialistas.

En el Continente americano se vienen realizando ferias de la ciencia, en forma sectorial y espontánea. En Argentina y Brasil han continuado realizándose con éxito ferias anuales y participando en ferias internacionales y continentales. Otros países como Uruguay, Chile, Venezuela y México, continúan realizando ferias de la ciencia anualmente.

En Colombia se han realizado seis ferias nacionales de la ciencia y dos olimpiadas científicas.

Estas ferias dan la posibilidad de agrupar los tres estamentos educativos: alumnos, profesores y padres de familia.

Una feria de la ciencia tiene diversas funciones:

- Funciones de tipo educativo: Desarrollo de actitudes hacia la ciencia, la tecnología y la investigación; desarrollo de la creatividad; estímulo al profesorado para enriquecer sus métodos de enseñanza y contribución al mejoramiento de la enseñanza de las ciencias.

- Funciones de tipo social: Integración de la comunidad educativa y contribución a la integración e igualdad social, al distinguir la excelencia académica y científica.

\section{- Funciones de tipo económico:}

Racionalización de los costos de operación y producción en razón a la metodología del proyecto y posibilidad de sustituir equipos sofisticados por sencillos y reproducibles, simplificando el costo de los equipos de laboratorio de ciencias, en los colegios.

A partir de 1975 el gobierno nacional suprimió la promoción y financiación de la Feria de la Ciencia a nivel nacional y aún no ha establecido oficialmente las razones y causas de orden científico o metodológico para esta determinación.

\footnotetext{
* Proyecto de investigación que se lleva a cabo en el Departamento de Física de la Universidad Pedagógica Nacional conjuntamente con la Asociación Colombiana para el Avance de la Ciencia, bajo el auspicio de COLCIENCIAS.
} 


\section{Objetivos}

\section{A. Objetivo General}

El objetivo general propuesto es el de encontrar respuesta a las preguntas siguientes:

- ¿Qué factores de orden objetivo, metodológico, científico, incidieron en la suspensión de la realización de la Feria Nacional de la Ciencia?

— ¿Qué actividad científica alternativa podría cumplir las funciones de la Feria Nacional de la Ciencia?

- ¿Bajo qué condiciones se podría restablecer la Feria Nacional de la Ciencia, para que cumpla los objetivos de promoción científica del estudiante?

- ¿Cómo podría la población estudiantil iniciarse en el conocimiento y ejercicio del método científico, cuando la escuela no ha alcanzado a cumplir ese punto?

\section{B. Objetivos Específicos}

Como objetivos particulares, la investigación se propone:

-Recoger información sobre posibilidades de orden administrativo, financiero, organizativo, social, educativo y sus respectivos problemas para la realización de dicho evento.

- Establecer las ventajas y desventajas de la inversión pública en financiar esta actividad frente a la inversión en otras actividades que pudieran cumplir fines similares.

—Describir las características y rasgos ideales de una Feria Nacional de la Ciencia en Colombia.

—Describir y formular un modelo de organización, desarrollo y ejecución de una feria.

- Presentar sugerencias y presupuestos para la continuación de este evento, si ello se encontrare aconsejable.

\section{Metodología}

Es una investigación descriptiva que busca establecer relaciones y correlaciones entre los factores que en forma integrada participan en el proceso enseñanza-aprendizaje de las ciencias, en los niveles primario y medio.

Entre los factores antes mencionados, como elementos que contribuyen al mejoramiento de la enseñanza de las ciencias, deben distinguirse los componentes formales o clásicos, (profesores, textos laboratorios), de los no formales (concursos o ferias científicas, conferencias, cine, exposiciones y juegos educativos con orientación científica). 
La capacitación y mejoramiento del profesorado en ciencias, la elaboración de textos, el diseño y uso de laboratorios, son temas que merecen estudios separados, en los cuales se supone que el Ministerio de Educación, a través de sus Divisiones especializadas, ya está trabajando. Por consiguiente, no forman parte de esta investigación.

Entre los factores extracurriculares que pueden contribuir a la optimización del proceso enseñanza-aprendizaje en ciencias, se destacan los concursos y ferias científicas por su característica de estimulación, a la creatividad y el interés científico. Como se vio al enunciar los postulados antes definidos, la feria de la ciencia no solo contribuye al mejoramiento de la enseñanza, sino que ejerce otras funciones de tipo educativo, social y económico. Por estas razones, la presente investigación se centrará en el examen de los factores no formales o extracurriculares $\mathrm{y}$, particularmente, en el evento denominado: "Feria de la Ciencia".

La investigación tendrá un carácter exploratorio, en el sentido de que se buscará, a través de un examen bibliográfico, de entrevistas y otros trabajos de campo, identificar variables que incidan en el funcionamiento de la feria de la ciencia.

Se tendrán en cuenta, en el territorio nacional, los estudiantes de bachillerato que han participado o no en las ferias nacionales, así como los profesores universitarios y de educación media, que han actuado como jurados y expositores. El estudio comprenderá las siguientes áreas: Física, Química, Matemáticas, Biología, Ciencias Sociales, Ciencias Vocacionales, Tecnología Educativa. 